\title{
Remote control on the reef: Clownfish and anemone microbiomes converge without contact
}

Émie Audet-Gilbert

François-Étienne Sylvain

Sidki Bouslama

Nicolas Derome

\section{Video Byte}

Keywords: microbiota, Microbiome, clownfish, anemone, Amphiprion percula, Heteractis magnifica, Cellulophaga, Flavobacteriaceae, symbiosis, mutualism, reef, chemical camouflage, chemical camouflage hypothesis, molecular mimicry, epithelial microbiome, chemical communication, microbiome restructuring, microbiota restructuring, clown fish, sea anemone, orange clownfish, magnificent sea anemone

Posted Date: October 16th, 2021

DOl: https://doi.org/10.21203/rs.3.rs-979151/v1

License: (a) This work is licensed under a Creative Commons Attribution 4.0 International License. Read Full License 


\section{Abstract}

The clownfish-anemone relationship is a well-known and charismatic example of mutualism. Clownfish excrete nutrients that feed anemones' symbiotic algae. While anemones' stinging cells protect clownfish from predators. How clownfish protect themselves from getting stung is unclear, but "chemical camouflage" of the fish's skin mucus is thought to play a role, possibly through changes in the mucus microbiome. A recent metataxonomics study investigated whether clownfish and anemones can change each other's surface microbiomes with or without physical contact. The researchers found that the microbiomes of paired clownfish and anemones began to converge, becoming more similar with time, even when the animals were not in direct contact. The microbiome convergence persisted for two weeks after the clownfish and anemone in each pair were separated, and the changes mainly involved the increase in abundance of three Flavobacteriacea bacterial strains related to Cellulophaga tyrosinoxydans. Although further research is needed to determine whether such microbiome convergence is required for clownfish-anemone mutualism, the results reveal that clownfish and anemones can influence each other's surface bacterial communities remotely and indicate that the skin microbiomes of both partners may play a role in successful symbiosis. 